\begin{tabular}{c} 
Brazilian Journal \\
of Chemical \\
Engineering \\
\hline
\end{tabular}

ISSN 0104-6632

Printed in Brazil

www.abeq.org.br/bjche

Vol. 28, No. 02, pp. 181 - 188, April - June, 2011

\title{
SUCCESSIVE CYCLES OF UTILIZATION OF NOVOZYM 435 IN THREE DIFFERENT REACTION SYSTEMS
}

\author{
L. Lerin ${ }^{1}$, G. Ceni $^{2}$, A. Richetti ${ }^{2}$, G. Kubiak ${ }^{2}$, J. Vladimir Oliveira ${ }^{2}$, \\ G. Toniazzo ${ }^{2}$, H. Treichel ${ }^{2 *}$, E. G. Oestreicher ${ }^{1}$ and D. Oliveira ${ }^{2}$ \\ ${ }^{1}$ Universidade Federal do Rio de Janeiro, Instituto de Química, \\ Cidade Universitária, 21941-909, Rio de Janeiro - RJ, Brasil. \\ ${ }^{2}$ Universidade Regional Integrada do Alto Uruguai e das Missões, URI, Campus de Erechim, \\ Av. 7 de Setembro 1621, 99700-000, Erechim - RS, Brasil. \\ E-mail: helen@uricer.edu.br
}

(Submitted: December 2, 2010 ; Revised: December 22, 2010 ; Accepted: February 7, 2011)

\begin{abstract}
The main focus of this work was to investigate the residual esterification activity and the product conversion after 10 successive cycles of utilization of a commercial lipase in three systems: esterification of 2-ethyl hexanol and palmitic acid in a solvent-free system; esterification of ascorbic acid and palmitic acid in tert-butanol; and transesterification of glycerol and methyl benzoate in 2-propanol. These systems were chosen based on previous results by our research group in terms of product conversion. Before scale-up, there is a need for evaluating several cycles of utilization of the biocatalyst. The esterification of 2-ethyl hexanol showed that after 10 cycles the enzyme retained $90 \%$ of its activity. The system consisting of ascorbic acid, palmitic acid, Novozym 435 and tert-butanol showed that a reduction in enzyme activity was accompanied by a reduction in reaction conversion; the same behavior was not observed for the third system.

Keywords: Lipase; Transesterification; Reuse.
\end{abstract}

\section{INTRODUCTION}

Lipases, also known as triacylglycerol ester hydrolases, are enzymes that cleave the ester bonds of triacylglycerols, with the subsequent release of free fatty acids, diacylglycerols, monoacylglycerols and glycerol. Lipases are also able to catalyze the reverse reactions (esterification, interesterification and transesterification), provided that the aqueous medium is replaced by an organic or a biphasic aqueous/organic medium. Although ester synthesis can be chemically catalyzed by acids or bases, the use of enzyme technology offers environmental advantages and a reduction in energy consumption. Furthermore, lipases show high selectivity, including stereo-selectivity, and give products of high purity and improved quality (Kato et al., 1999; Richetti et al., 2010; Richetti et al., 2010; Barros et al., 2010; Pereira et al., 2003).

A range of fatty acid esters is now being produced commercially using immobilized lipase in non-aqueous solvents. For example, esters produced from long-chain fatty acids (12-20 carbon atoms), as well as short-chain fatty acids ( $2-8$ carbon atoms), are increasingly used in the food, detergent, plasticizer, lubrificant, cosmetic and pharmaceutical industries (Vedejs and Jure, 2005; Oliveira et al., 2006; Gottor, 1999).

Loss of enzyme activity with time can be caused by deactivation of the enzyme as a consequence of thermal effects and product concentration. Knowledge of the rate law governing the deactivation process is often important in enzymecatalyzed processes and of interest in process design.

*To whom correspondence should be addressed 
One of the problems that arises when one tries to evaluate the loss of enzyme activity in batch reactors is the fact that the time of the reaction and the time at which the set of experiments is started are equivalent. This fact does not permit one to separate the rate of the reaction from the rate at which the enzyme is losing activity because both processes occur simultaneously. One strategy to overcome this problem is to carry out several cycles of reaction with the same batch of lipase. Hence, it is possible to distinguish between the time characteristic of the reaction (reaction time) and that corresponding to lipase deactivation (the time elapsed since the start of the first experiment). Each cycle involves the same elapsed time for the reaction, but this elapsed time will differ from the time during which the lipase has been susceptible to deactivation (Theil, 1995; Saxena et al., 2003; Ceni et al., 2010).

In this context, the main focus of this work was to investigate the residual esterification activity and the product conversion after 10 successive cycles of utilization of a commercial immobilized lipase (Novozym 435) in three important reaction systems: esterification of 2-ethyl hexanol and palmitic acid in a solvent-free system for 2-ethylhexyl palmitate production; esterification of ascorbic acid and palmitic acid in tert-butanol for ascorbyl palmitate production; and transesterification of glycerol and methyl benzoate in 2-propanol for production of 1 -glyceryl benzoate. These systems were chosen after recent works published by our research group (Richetti et al., 2010; Ceni et al., 2010; Lerin et al., 2011), where promising results were obtained in terms of product conversion and the fact that, before the scale-up of the enzymatic process, there was a need to evaluate several cycles of utilization of the biocatalyst by measurement of residual activity and reaction conversion after each cycle of use of the enzyme.

L-Ascorbic acid, a natural hydrophilic antioxidant, has been used but its application is limited in hydrophobic foods and cosmetics. Due to the steadily growing demand for natural materials, the synthesis of esters of ascorbic acid by lipasecatalyzed reactions has become of current commercial interest to be used as an antioxidant in the food, cosmetic and pharmaceutical industries (Viklund et al., 2003).

Fatty acid esters of 2-ethyl hexanol, such as 2-ethylhexyl palmitate, are of great interest due to their applications in the cosmetics, pharmaceutics, food and chemical industries. They are used, for example, as low temperature plasticizers for polyvinyl chloride, vinyl chloride, copolymers, polystyrene, ethyl cellulose and synthetic rubber, and also in the manufacture of water-resistant lubricants or as solvents (He et al., 2002; Tan et al., 2006).

1-Glyceryl benzoate is a medically important compound since it is a natural choice to replace epichlorohydrin as a green intermediate for betablocker production, typified by carvedilol and propranolol (Brockerhoff and Jensen, 1974). The antagonists of beta-adrenergic receptors (betablockers), such as propranolol (Howe and Rao, 1968) and carvedilol, are important active pharmaceutical ingredients (APIs) used in the treatment of diseases like hypertension, cardiopathies, some kinds of hyh and glaucoma.

\section{MATERIALS AND METHODS}

\section{Substrates and Solvents}

\section{For Enzymatic Esterification of 2-Ethyl Hexanol and Palmitic Acid in Solvent-Free System}

Commercial palmitic acid (Vetec, 98\% purity) and 2-ethyl hexanol (Merck, 99\% purity).

\section{For Enzymatic Esterification of Ascorbic Acid and Palmitic Acid in Tert-Butanol System}

Commercial palmitic acid (Vetec, 98\% purity) and L-(+)-ascorbic acid (Vetec, 99\% purity) and tertbutanol (HPLC grade, Vetec) as solvent.

\section{For Enzymatic Transesterification of Glycerol and Methyl Benzoate in 2-Propanol System}

Glycerol and methyl-benzoate (Vetec, both 99.5\% purity) and n-propanol (HPLC grade, Vetec) as solvent.

\section{Enzyme}

Commercial lipase from Candida antarctica (Novozym 435), immobilized on a macroporous anionic resin $(0.12 \mathrm{U} / \mathrm{g}, 1.4 \%$ water, diameter in the range of $0.3-0.9 \mathrm{~mm}$ and optimum temperature of $70^{\circ} \mathrm{C}$ ), was purchased from Novozymes (Araucária, PR, Brazil) and used as catalyst in all tested systems.

\section{Experimental Conditions for Enzyme Reuse in Each Experimental System}

The optimized experimental conditions for each reaction system were previously determined in 
recent works published in the literature (Richetti et al., 2010; Ceni et al., 2010; Lerin et al., 2011). In summary, the following conditions were used here for successive cycles of utilization of Novozym 435.

\section{For Enzymatic Esterification of 2-Ethyl Hexanol and Palmitic Acid in Solvent-Free System}

The optimum conditions for the production of 2-ethylhexyl palmitate were found to be: acid to alcohol molar ratio of 1:5.5, stirring rate of $150 \mathrm{rpm}, 70^{\circ} \mathrm{C}$, enzyme concentration of $10.5 \mathrm{wt} \%$ and 6 hours of reaction, resulting in a 2-ethylhexyl palmitate conversion of about $93 \%$ (Richetti et al., 2010).

\section{For Enzymatic Esterification of Ascorbic Acid and Palmitic Acid in Tert-Butanol System}

The optimum production of ascorbyl palmitate were achieved at an ascorbic acid to palmitic acid molar ratio of $1: 9$, stirring rate of $150 \mathrm{rpm}, 70^{\circ} \mathrm{C}$, enzyme concentration of $5 \mathrm{wt} \%$ at 17 hours of reaction, using tert-butanol as solvent, resulting in an ascorbyl palmitate conversion of about $67 \%$ (Lerin et al., 2011).

\section{For Enzymatic Transesterification of Glycerol and Methyl Benzoate in 2-Propanol System}

The optimum conditions were found to be a methyl benzoate to glycerol molar ratio of 1:1, stirring rate of $150 \mathrm{rpm}, 50^{\circ} \mathrm{C}$, enzyme concentration of $10 \mathrm{wt} \%$ at 24 hours of reaction, using 2-propanol as solvent, with a resulting conversion to 1 -glyceryl benzoate of about $29 \%$ (Ceni et al., 2010).

\section{Experimental Procedure for Enzyme Reuse}

Using the experimental conditions presented previously, successive cycles of utilization of Novozym 435 were carried out. A total of ten cycles was evaluated for each reaction system. Before starting the first reaction cycle, the enzyme was activated at $40^{\circ} \mathrm{C}$ for 60 minutes. After the predefined reaction time, established above for each different system, the enzyme was recuperated and kept in a desiccator for at least 24 hours. Then the enzyme was used in a new batch. The enzymatic activity was measured before and after each cycle and the residual activity was determined following the methodology described below. The product conversion in each cycle was also evaluated.

\section{Analytical}

\section{Quantification of Reaction Products}

For Enzymatic Esterification of 2-Ethyl Hexanol and Palmitic Acid in a Solvent-Free System

Quantitative analyses of the products were conducted using an HPLC system from Agilent, equipped with a refractive index detector. The following instrumentation and conditions were used: Zorbax C18 column $(4.6 \mathrm{~mm}$ x $250 \mathrm{~mm}, 5 \mu \mathrm{m})$, flow rate of $1.0 \mathrm{~mL} / \mathrm{min}$, column temperature of $35^{\circ} \mathrm{C}$ and the mobile phase, acetonitrile:methanol: $\mathrm{H}_{2} \mathrm{O}$ $(75: 25: 5, \mathrm{v} / \mathrm{v} / \mathrm{v})$. The mobile phase was used as the sample dissolving solvent and the injection volume was $20 \mu \mathrm{L}$. Quantification was carried out using authentic standards of 2-ethylhexyl palmitate (Sigma-Aldrich). Calibration curves were constructed with the following concentrations 1410; $2820 ; 5640 ; 11280 ; 16920 ; 22560 ; 28200$ and 33840 ppm. Reaction conversion was calculated based on the content of 2-ethylhexyl palmitate in the sample analyzed and on the reaction stoichiometry (Richetti et al., 2010).

\section{For Enzymatic Esterification of Ascorbic Acid and Palmitic Acid in Tert-Butanol}

Quantitative analyses of the products were conducted using an HPLC system from Agilent, equipped with a refractive index detector. The following instrumentation and conditions were used: Zorbax $\mathrm{C}_{18}$ column $(4.6 \mathrm{~m} \times 250 \mathrm{~mm}, 5 \mu \mathrm{m})$, flow rate of $1.0 \mathrm{~mL} / \mathrm{min}$, column temperature of $35^{\circ} \mathrm{C}$; the mobile phase, acetone:methanol: $\mathrm{H}_{2} \mathrm{O}$ with $0.5 \%$ acid acetic $(75: 25: 5, \mathrm{v} / \mathrm{v} / \mathrm{v})$. The mobile phase was used as the sample dissolving solvent and the injection volume was $20 \mu \mathrm{L}$. Quantification was carried out using authentic standards of ascorbyl palmitate (6-O-palmitoyl-L-ascorbic acid) (SigmaAldrich). Calibration curves were built with the product concentrations of $240 ; 480 ; 960 ; 1920$; $2880 ; 3840$ and $4800 \mathrm{ppm}$. Reaction conversion was calculated based on the content of ascorbyl palmitate in the sample analyzed and the reaction stoichiometry (Lerin et al., 2011).

\section{For Enzymatic Transesterification of Glycerol and Methyl Benzoate in 2-Propanol}

The reactional medium, without enzyme, was rotary-evaporated and diluted in methanol for the chemical analysis, performed with a gas 
chromatograph (Shimadzu Model GC 17-A) equipped with a capillary column of Wcot Fused Silica $(30 \mathrm{~m} \times 0.32 \mathrm{~mm})$ containing GP-Sil 5CB. The column was kept at $40^{\circ} \mathrm{C}$ for 1 minute, heated to $125^{\circ} \mathrm{C}$ at a rate of $10^{\circ} \mathrm{C} / \mathrm{min}(2 \mathrm{~min})$ and, then, heated again to $250^{\circ} \mathrm{C}$ at the same rate $\left(10^{\circ} \mathrm{C} / \mathrm{min}\right)$. The detector and injector temperatures were kept at $300^{\circ} \mathrm{C}$. The column pressure and the hydrogen flow rate were $8 \mathrm{KPa}$ and $3.5 \mathrm{~mL} / \mathrm{min}$, respectively. The split ratio was 1:60. The standard sample of 1-glyceryl benzoate was synthesized in our laboratory and the structure of the compound was confirmed by NMR: ${ }^{1} \mathrm{H}-\mathrm{NMR}$ registered on a Varian NMR $(200 \mathrm{MHz})$ in $\mathrm{CDCl}_{3}$ solution with $\mathrm{CHCl}_{3}$ as internal reference and ${ }^{13} \mathrm{C}-\mathrm{NMR}$ on a Varian NMR $(50 \mathrm{MHz})$ in $\mathrm{CDCl}_{3}$ solution with $\mathrm{CHCl}_{3}$ as internal reference (Ceni et al., 2010).

\section{Lipase Esterification Activity}

The enzyme activity was determined as the initial rate of the esterification reaction between lauric acid and n-propanol at a molar ratio of 3:1, temperature of $60^{\circ} \mathrm{C}$ and enzyme concentration of $5 \mathrm{wt} \%$ in relation to the substrates. At the beginning of the reaction, samples containing the mixture of lauric acid and npropanol were collected and the lauric acid content was determined by titration with $0.04 \mathrm{~N} \mathrm{NaOH}$. After the addition of the enzyme to the substrates, the mixture was kept at $60^{\circ} \mathrm{C}$ for $15 \mathrm{~min}$. Then, the lauric acid consumption was determined. One unit of activity (U) was defined as the amount of enzyme necessary to consume $1 \mu \mathrm{mol}$ of lauric acid per minute (Oliveira et al., 2006). All enzymatic activity determinations were performed in at least three replicates.

\section{Recuperation of Enzymes After Each Cycle of Utilization}

After each cycle of utilization, the biocatalyst was separated from the reaction medium by filtration. Then, the catalyst was washed twice using $10 \mathrm{~mL}$ of n-hexane $(99 \%$, Vetec) and the sample was vacuum filtered. This procedure is a modification of the method proposed by Castro \& Anderson (1995) that used n-heptane as the washing agent. The enzyme was then dried in oven at $40^{\circ} \mathrm{C}$ for 1 hour. The recovered enzyme was kept in a desiccator for 24 hours and, after this period of time, an aliquot of $0.2 \mathrm{~g}$ of the enzyme was used for determination of esterification activity. The remainding amount of the enzyme used in the previous batch was reutilized in a subsequent cycle for each reaction system evaluated in this work. The residual esterification activity was defined as the ratio of (Final activity/Initial activity) x 100 and determined after each cycle of utilization of the enzyme.

\section{RESULTS AND DISCUSSION}

The use of immobilized enzymes in synthetic reactions presents, as a main advantage, the possibility of reuse in successive cycles. Here 10 cycles of utilization of a commercial immobilized lipase were carried out for three different reaction systems, aiming at evaluating the residual enzyme activity and reaction conversion. Figures 1,2 and 3 present the results obtained for each system.

Figure 1 indicates that the reaction system using palmitic acid and 2-ethyl hexanol as substrates and Novozym 435 in a solvent-free system presented a residual enzyme activity of almost $100 \%$ after 5 cycles of utilization. After 10 cycles of utilization, a residual activity of about $90 \%$ was obtained. Conversion remained practically constant after these 10 cycles. Because a solvent-free system was tested, a low reduction in enzyme activity was observed.

Figure 2 shows that, for the reactional system of ascorbic acid and palmitic acid, with Novozym 435 and tert-butanol as catalyst and solvent, respectively, the residual enzyme activity was nearly $100 \%$ after 4 cycles of utilization (each cycle of 17 hours). As of the fifth cycle, there was a reduction in enzyme activity, accompanied by a reduction in reaction conversion. Here it seems that the enzyme activity is directly related to the product conversion.

In the experiments on enzymatic production of 1-glyceryl benzoate, Figure 3 shows that the enzyme kept its initial activity for 4 cycles of utilization (about 100\% of residual activity after each cycle of 24 hours). From the fifth cycle on, a loss of enzyme activity was observed (from 30 to $40 \%$, until 10 cycles of utilization). The conversion to 1-glyceryl benzoate remained constant after 10 cycles of enzyme utilization (about 13.5\%). In the range evaluated, the reduction in enzyme activity did not affect the product conversion. A possible explanation for this fact in this reaction system would be an excess of enzyme under the initial experimental conditions, so that a reduction on enzyme activity was not enough to reduce the process conversion. 


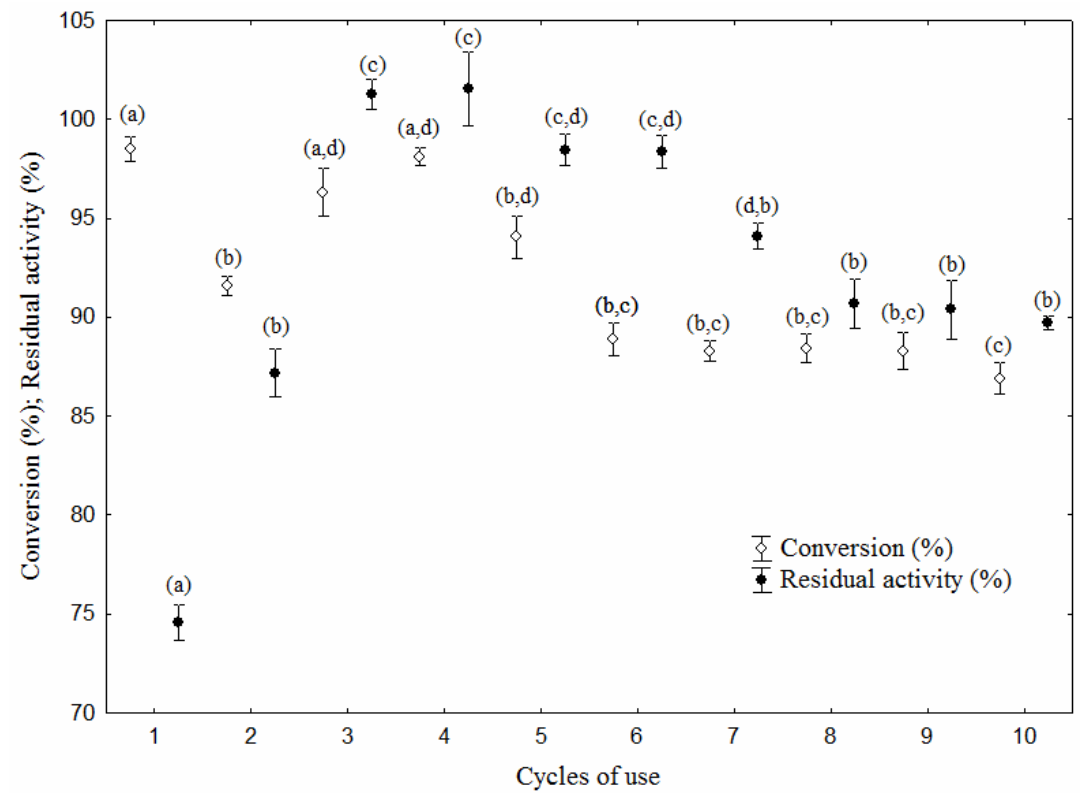

Figure 1: Cycles of reuse of Novozym 435 for 2-ethylhexyl palmitate production. Experimental conditions: acid to alcohol molar ratio of 1:5.5, stirring rate of $150 \mathrm{rpm}$, $70^{\circ} \mathrm{C}$, enzyme concentration of $10.5 \mathrm{wt} \%$ and 6 hours of reaction in a solvent-free system. Results are expressed by mean and respective standard error (bars) and different letters (for each response) indicate values that differ statistically $(\mathrm{p}<0.05)$ by analysis of variance followed by Tukey's test.

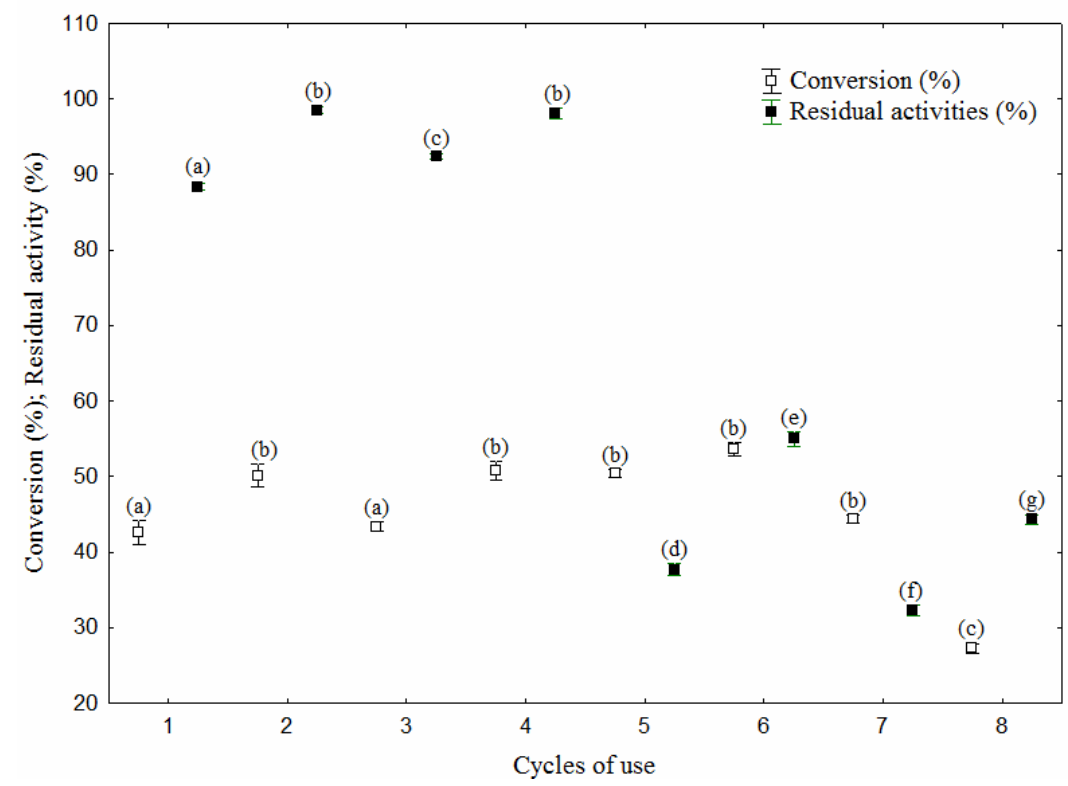

Figure 2: Cycles of reuse of Novozym 435 for ascorbyl palmitate production. Experimental conditions: ascorbic acid to palmitic acid molar ratio of 1:9, stirring rate of $150 \mathrm{rpm}, 70^{\circ} \mathrm{C}$, enzyme concentration of $5 \mathrm{wt} \%$ at 17 hours of reaction, using tert-butanol as solvent. Results are expressed by mean and respective standard error (bars) and different letters (for each response) indicate values that differ statistically $(\mathrm{p}<0.05)$ by analysis of variance followed by Tukey's test. 


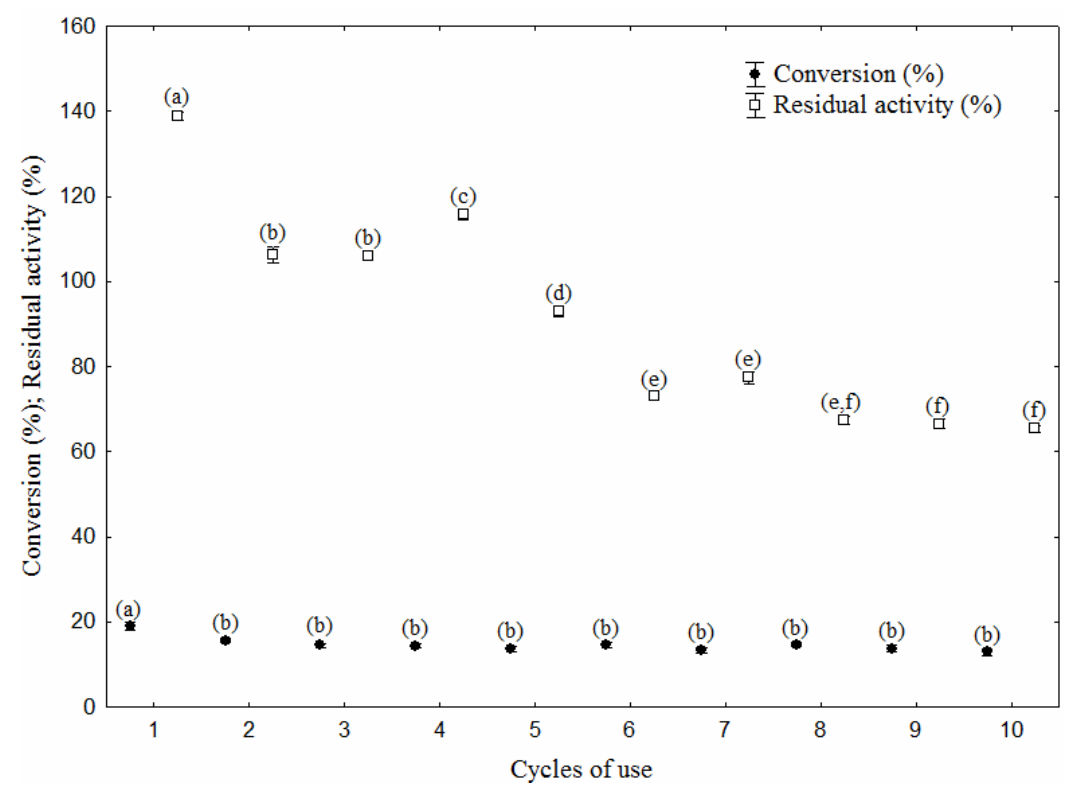

Figure 3: Cycles of reuse of Novozym 435 for 1-glyceryl benzoate production. Experimental conditions: methyl benzoate to glycerol molar ratio of $1: 1$, stirring rate of $150 \mathrm{rpm}, 50^{\circ} \mathrm{C}$, enzyme concentration of $10 \mathrm{wt} \%$ at 24 hours of reaction, using 2-propanol as solvent. Results are expressed by mean and respective standard error (bars) and different letters (for each response) indicate values that differ statistically $(\mathrm{p}<0.05)$ by analysis of variance followed by Tukey's test.

From the results presented in this work, it is possible to conclude that the residual enzyme activity and the product conversion are directly dependent on the substrates and solvents employed for the execution of the reaction.

The use of organic solvents as reaction media for enzymatic reactions provides numerous industrially attractive advantages compared to traditional aqueous reaction systems, such as enhancement of the solubility of the substrates, the reversion of the thermodynamic equilibrium, the suppression of water-dependent reactions and the elimination of microbial contamination. However, some disadvantages can be cited, such as inactivation of the enzymes, labor and cost-intensive preparation of biocatalysts in form of covalently-modified systems, mass-transfer limitations in the case of heterogeneous systems or of viscous solvents, and water activity control needed for processes involving condensation reactions (Doukyu and Ogino, 2010). The step of selecting an appropriate organic solvent is a crucial factor in enzymatic catalysis in nonaqueous media, due to the direct interference of this choice on activity, stability and specificity of the enzyme. In general, hydrophobic solvents are less harmful to the enzymes and the water necessary to maintain the structure of the enzyme. Hydrophilic solvents tend to strip the essential water from the proteic structure, resulting in loss of enzyme activity (De Paula et al., 2005). An ideal organic solvent will also dissolve the substrate well, favoring the progress of the reaction without affecting the enzymatic activity (Tsukamoto, 2006).

The specialized literature points out that, of all the usual parameters such as dielectric constant, dipole moment, hydrogen bonding, or polarity, the logarithm of the ethanol-water partition coefficient $(\log \mathrm{P})$ gives the best correlation with the enzyme activity (Yang and Robb, 1994). In general, for the optimization of biocatalytic systems in organic solvents, $\log \mathrm{P}$ is considered to be a good quantitative parameter since it represents the polarity of the solvent. The following classification is recommended for choosing the most adequate organic solvents for enzymatic catalysis: (i) solvents with $\log \mathrm{P}<2$, due to their high polarity, can cause the denaturation of the catalyst; (ii) solvents with $2<\log \mathrm{P}<4$ are considered to be moderate; and (iii) solvents with $\log \mathrm{P}>4$ can be considered to be the most appropriate since they are non-polar 
(Tsukamoto, 2006). Tsukamoto (2006) thus affirms that solvents with $\log \mathrm{P}<2$ are not appropriate for biocatalytic purposes, while those with $\log \mathrm{P}>4$ (apolar) can be considered ideal.

In spite of the relevance of determining the number of cycles of utilization of a biocatalyst before scale-up of the process, very few works concerning this subject were found in the literature. As an example, Hajar et al. (2009) evaluated the cycles of reuse of Novozym 435 for the methanolysis of canola oil in a solvent-free system. The reaction was conducted for 5 successive cycles or a total of 432 hours and conversion remained at about $97 \%$. The authors did not determine the residual activity of the biocatalyst.

Ghamgui et al. (2006) studied the cycles of reuse of a lipase from Staphylococcus simulans immobilized on sodium carbonate. After 4 cycles, no significant difference was observed in the production of isoamyl acetate at $37^{\circ} \mathrm{C}$. After 10 cycles, a reduction of about $50 \%$ in the conversion was observed and the residual activity was $76 \%$.

Brígida et al. (2008) evaluated the use of coconut fiber residue as a support for immobilization of lipase from Candida antarctica type B (CALB). The authors studied the cycles of reuse of the immobilized enzyme and compared the results with those obtained for Novozym 435. After three cycles of hydrolysis, the immobilized lipase presented residual activity lower than 50\%. Novozym 435, under the same experimental conditions, retained more than $70 \%$ of its activity after ten cycles. However, for the synthesis of butyl butyrate, the CALB lipase immobilized on coconut fiber showed good stability compared to Novozym 435, keeping $80 \%$ of its initial activity after 6 successive cycles of utilization. The authors concluded that the stability of the enzyme depends on the reaction system under investigation.

The work of Gomes et al. (2004) evaluated the influence of the reaction temperature and substrate polarity on non-conventional biocatalysis by Candida rugosa lipase immobilized on chitin functionalized with hexamethylenediamine followed by glutaraldehyde activation. Production of butyl esters was found to be dependent on the substrate partition coefficient, which was the greatest for the system butanol and butyric acid.

\section{CONCLUSIONS}

New experimental data on residual esterification activity and product conversion after 10 successive cycles of utilization of a commercial immobilized lipase (Novozym 435) are reported in this worh for three important reactional systems, information relevant for the scale-up of processes using this commercial enzyme. The esterification of 2-ethyl hexanol and palmitic acid for 2-ethylhexyl palmitate production in a solvent-free system showed that, after 10 cycles, the enzyme retained $90 \%$ of its activity. Considering the system consisting of ascorbic acid, palmitic acid, Novozym 435 and tertbutanol, a reduction in enzyme activity was accompanied by a reduction in reaction conversion. The production of 1-glyceryl benzoate in 2-propanol showed that the reduction in enzyme activity did not affect the product conversion.

\section{ACKNOWLEDGEMENTS}

The authors dedicate this work to the memory of Professor Octavio Augusto Ceva Antunes (and his wife and little boy), whose lives were too prematurely taken away from our existence one year ago, in the Air France flight 477 tragedy. Professor Antunes will remain a reference as scientist, an unforgettable friend, and an example of courage, always enlightening us with his experience and creativeness.

The authors also thank the CNPq, CAPES and FAPERGS for financial support of this work and scholarships.

\section{REFERENCES}

Barros, M., Fleuri, L. F., Macedo, G. A., Seed lipases: sources, applications and properties - a review. Brazilian Journal of Chemical Engineering, 27, (1), 15-29 (2010).

Brígida, A. I. S., Pinheiro, A. D. T., Ferreira, A. L. O. and Gonçalves, L. R. B., Immobilization of Candida antarctica Lipase B by adsorption to green coconut fiber. Applied Biochemistry and Biotechnology, 146, 173 (2008).

Brockerhoff, H. E., Jensen, R. G., Lipases. New York, Academic Press (1974).

Castro, H. F. and Anderson, W. A., Fine chemicals by biotransformation using lipase. Química Nova, 18, 544 (1995).

Ceni, G., Lerin, L.A., Conto, J. F., Brancher, C. V., Silva, P. C., Toniazzo, G., Treichel, H., de Oliveira, D., Oliveira, J. V., Oestreicher, E. G. and Antunes, O. A. C., Optimization of 1glyceryl benzoate production by enzymatic 
transesterification in organic solvents. Enzyme and Microbial Technology, 46, 107 (2010).

De Paula, A. V., Barboza, J. C. S., Castro, H. F., Estudo da influência do solvente, carboidrato e ácido graxo na síntese enzimática de ésteres de açúcares. Química Nova, 28, 792 (2005).

Doukyu, N. and Ogino, H., Organic solvent-tolerant enzymes. Biochemical Engineering Journal, 48, 270 (2010).

Ghamgui, H., Karra-Chaâbouni, M., Bezzine, S., Miled, N. and Gargouri, Y., Production of isoamyl acetate with immobilized Staphylococcus simulans lipase in a solvent-free system. Enzyme and Microbial Technology, 38, 78 (2006).

Gomes, F. M., Pereira, E. B. and Castro, H. F., Immobilization of lipase on chitin and its use in nonconventional biocatalysis. Biomacromolecules, 5, 17 (2004).

Gotor-Férnandez, V., Brieva, R. and Gotor, V., Lipases: Useful biocatalysts for the preparation of pharmaceuticals. Journal of Molecular Catalysis B: Enzymatic, 40, 111 (2006).

Hajar, M., Shokrollahzadeh, S., Vahabzadeh, F. and Monazzami, A., Solvent-free methanolysis of canola oil in a packed-bed reactor with use of Novozym 435 plus loofa. Enzyme and Microbial Technology, 45, 188 (2009).

He, X. L., Chen, B. Q. and Tan, T. W., Enzymatic synthesis of 2-ethylhexyl esters of fatty acids by immobilized lipase from Candida sp. 99-125. Journal of Molecular Catalysis B: Enzymatic, 18, 333 (2002).

Howe, R. and Rao, B. S., Beta-Adrenergic blocking agents. III. The optical isomers of pronethalol, propranolol, and several related compounds. Journal of Medical Chemistry, 11, 1118 (1968).

Kato, Y., Fujiwara, I. and Asano, Y., Synthesis of optically active a-monobenzoyl glycerol by asymmetric transesterification of glycerol. Journal of Molecular Catalysis B: Enzymatic, 9, No. 4-6, 193 (2000).

Lerin, L., Richetti, A., Dallago, R. M., Treichel, H., Oestreicher, E. G. O., Mazutti, M. A., de Oliveira, D., Oliveira, J. V. and Antunes, O. A. C., Enzymatic synthesis of ascorbyl palmitate in organic solvents: Process optimization and kinetic evaluation. Food and Bioprocess Technology, DOI 10.1007/s1 1947-010-0398-1.
Oliveira, D., Freire, D. M. G., Oliveira, J. V., Dariva, C., Feihrmann, A. C., Cunha, A. G., Beviláqua, J. V. and Destain, J., Influence of compressed fluids treatment on the activity of Yarrowia lipolytica lipase. Journal of Molecular Catalysis B: Enzymatic, 39, 117 (2006).

Pereira, E. B., Zanin, G. M., Castro, H. F., Immobilization and catalytic properties of lipase on chitosan for hydrolysis and esterification reactions. Brazilian Journal of Chemical Engineering 20, (4), 343-355 (2003).

Richetti, A., Leite, S. G. F., Antunes, O. A. C., de Souza, A. L. F., Lerin, L., Treichel, H., Oestreicher, E. G. and Oliveira, D., Optimization of 2-ethylhexyl palmitate production using Lipozyme RM IM as catalyst in a solvent-free system. Applied Biochemistry and Biotechnology, 160, No. 8, 2498 (2010).

Richetti, A., Leite, S. G. F., Antunes, O. A. C., de Souza, A. L. F., Lerin, L., Dallago, R. M., Emmerich, D., Di Luccio, M., Treichel, H., Oliveira, J. V. and Oliveira, D., Assessment of process variables on 2-ethylhexyl palmitate production using Novozym 435 as catalyst in a solvent-free system. Bioprocess and Biosystems Engineering, 33, 331 (2010).

Saxena, R. K., Davidson, W. S., Sheoran, A. and Giri, B., Purification and characterization of an alkaline thermostable lipase from Aspergillus carneus. Process Biochemistry, 39, 239 (2003).

Tan, T., Chen, B. Q. and Ye, H., Enzymatic synthesis of 2-ethylhexyl palmitate by lipase immobilized on fabric membranes in the batch reactor. Biochemical Engineering Journal, 29, 41 (2006).

Tail, F., GA-72M, A cancer associated antigen, and uses thereof. Chemical Reviews, 95, 2203 (1995).

Tsukamoto, J., Esterificação enzimática direta de carboidratos com ácido acrílico em meio orgânico. Tese de doutorado- Unicamp, Campinas SP (2006).

Vedejs, E. and Jure, M. A., Efficiency in nonenzymatic kinetic resolution. Chemie International, 44, 3974 (2005).

Viklund, F., Alander, J. and Hult, K., Antioxidant properties and enzymatic synthesis of ascorbyl fatty acid esters. Journal of American Oil Chemist's Society, 80, 795 (2003). 